\title{
Collagenous Sprue
}

National Cancer Institute

\section{Source}

National Cancer Institute. Collagenous Sprue. NCI Thesaurus. Code C45426.

A rare disorder affecting the digestive tract. Its cause is unclear but may be attributed, in part, to increased collagen synthesis without adequate fibrolysis. It is characterized histologically by atrophy of mucosal villi and crypts with extensive subepithelial collagen deposition. Clinical signs include nausea, vomiting, diarrhea and weight loss. Unlike celiac sprue (celiac disease), a gluten-free diet does not predict a certain regression of the disease. The clinical course follows a progression of malabsorption leading to nutritional deficiencies, small bowel ulceration/perforation, lymphoma and infection. Prognosis is usually dismal. 